\title{
Size of Inoculum and Nitrogen Metabolism in Aspergillus oryzae
}

\author{
By A. F. McINTOSH AND J. MEYRATH \\ Department of Applied Microbiology and Biology, Royal College of Science \\ and Technology, Glasgow
}

(Received 4 March 1963)

\section{SUMMARY}

The influence of size of inoculum on the nitrogen metabolism of Aspergillus oryzae in submerged culture was studied. In producing a given weight of mycelium a large-inoculum culture, as compared with a smallinoculum culture, showed a higher degree of assimilation of nitrogen and a lower excretion of nitrogen over most of the growth curve. This comparatively greater efficiency of the large-inoculum culture became more pronounced when mechanical stress in the culture was increased. Under high mechanical stress, the inefficiency of a small-inoculum culture was so marked that in forming unit weight of mycelium it utilized more inorganic nitrogen than did a large-inoculum culture.

\section{INTRODUCTION}

Previous work on Aspergillus oryzae (Meyrath, 1962, 1963) showed that inoculum size had an important bearing upon multiplication rate in the exponential phase, growth rate in the linear phase and maximum yield. Later (Meyrath \& McIntosh 1963), it was shown that the carbon metabolism was less efficient in small-inoculum cultures. In an attempt to discover whether this inefficiency extended to other metabolic processes, the nitrogen metabolism of large-inoculum and small-inoculum cultures was examined under a variety of conditions. This work is reported here.

\section{METHODS}

Materials. The strain of Aspergillus oryzae used previously (Meyrath, 1962, 1963; Meyrath \& McIntosh, 1963) was used again. In all experiments, the inoculum consisted of conidia; the preparation of a conidial inoculum has been described (Meyrath \& McIntosh, 1963). The substrate contained per l.: starch, 10 g.; $\left(\mathrm{NH}_{4}\right)_{2} \mathrm{SO}_{4}$, 1 g.; $\mathrm{MgSO}_{4} .7 \mathrm{H}_{2} \mathrm{O}, 0 \cdot 3$ g.; $\mathrm{Na}_{2} \mathrm{HPO}_{4}, 4.73$ g.; $\mathrm{KH}_{2} \mathrm{PO}_{4}$, 4.54 g.; trace elements : $\mathrm{FeCl}_{3} .6 \mathrm{H}_{2} \mathrm{O}, 15 \mathrm{mg}$; $\mathrm{CuSO}_{4} .5 \mathrm{H}_{2} \mathrm{O}, 50 \mu \mathrm{g}$; $\mathrm{MnSO}_{4} \cdot 4 \mathrm{H}_{2} \mathrm{O}, 50 \mu \mathrm{g}$; $\mathrm{ZnSO}_{4} .7 \mathrm{H}_{2} \mathrm{O}$, $500 \mu \mathrm{g}$.; $\mathrm{CaCl}_{2} \cdot 6 \mathrm{H}_{2} \mathrm{O}, 1 \mathrm{mg}$. (see substrate A 4, Meyrath \& $\mathrm{McIntosh}, 1963$ ).

Procedure. 5 l. quantities of substrate were prepared and maintained at $25^{\circ}$ in 6 l. triple-neck flasks fitted with an aerating mechanism, a sampling device and a Vibro-Mix unit (made by AG. für Chemie-Apparatebau, Männedorf, Zürich, Switzerland). The amplitude of the vibrator was adjusted to $2 \mathrm{~mm}$. (high mechanical stress) or $1 \mathrm{~mm}$. (low mechanical stress). The substrate received an inoculum of $2 \times 10^{7}$ conidia $/ 100 \mathrm{ml}$. (large-inoculum experiments) or $4 \times 10^{3}$ conidia/100 ml. (small-inoculum experiments), the inoculum having a volume of $50 \mathrm{ml}$. in each case. 
The volume of sample taken depended on the mycelial content; samples were usually taken in duplicate or triplicate. The technique for collecting mycelium was described by Meyrath \& McIntosh (1963). The mg. dry wt. mycelium in samples from submerged cultures was estimated at intervals to construct a growth curve. At various stages of growth, attention was focussed on three aspects of nitrogen metabolism: organic- $\mathrm{N}$ in mycelium, organic- $\mathrm{N}$ in culture filtrate, ammonia- $\mathrm{N}$ utilized.

Estimation of nitrogen. Where ammonia-N only was to be estimated, concentrated $\mathrm{NaOH}$ solution was added to make the mixture alkaline towards phenolphthalein; ammonia was steam distilled and collected in $50 \mathrm{ml}$. boric acid solution $\left(\mathrm{H}_{3} \mathrm{BO}_{3}\right.$

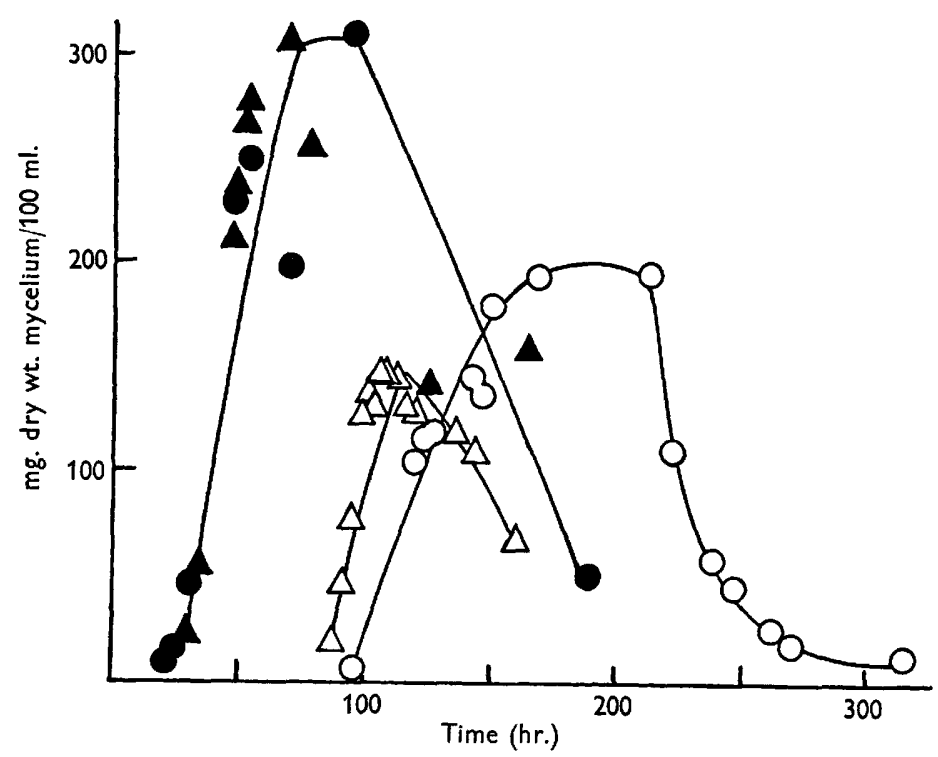

Fig. 1. Pattern of growth of Aspergillus oryzae. Large-inoculum cultures were grown under low ( - - ) and high ( $\Delta-\Delta)$ mechanical stress. Small-inoculum cultures were likewise grown under low $(\mathrm{O}-\mathrm{O})$ and high $(\triangle-\triangle)$ mechanical stress.

40 g./l.) which was then titrated with $0.02 \mathrm{~N}-\mathrm{H}_{2} \mathrm{SO}_{4}$ using methyl red indicator. Ammonia-N utilized was estimated on 5-20 ml. samples and calculated by subtracting the value for residual ammonia- $\mathrm{N}$ in the culture filtrate from that for initial ammonia- $\mathrm{N}$ in the substrate.

Where organic- $\mathrm{N}$ or total- $\mathrm{N}$ (organic- $\mathrm{N}$ and ammonia- $\mathrm{N}$ ) was to be estimated, digestion was first necessary to convert organic- $\mathrm{N}$ to ammonia- $\mathrm{N}$. The material was boiled in micro-Kjeldahl flasks with $2 \mathrm{ml}$. conc. $\mathrm{H}_{2} \mathrm{SO}_{4}$ containing traces of copper sulphate and selenium as catalysts until a clear solution was obtained. All the $\mathrm{N}$ was then in the form of ammonia- $\mathrm{N}$ and was estimated as above. The nitrogen of the mycelium was considered to be in organic form and the pellets were treated accordingly. Organic- $\mathrm{N}$ in the culture filtrate was estimated on 5-20 ml. samples and was calculated by subtracting the value for ammonia- $\mathrm{N}$ from that for total-N. 


\section{RESULTS}

The growth curves shown in Fig. 1 compare well with those obtained in earlier experiments. Maximum mycelial yield was greater when a large inoculum was used (Fig. 1). The difference in maximum mycelial yield as between large-inoculum and small-inoculum cultures was more pronounced when the mechanical stress was increased (Fig. 1).

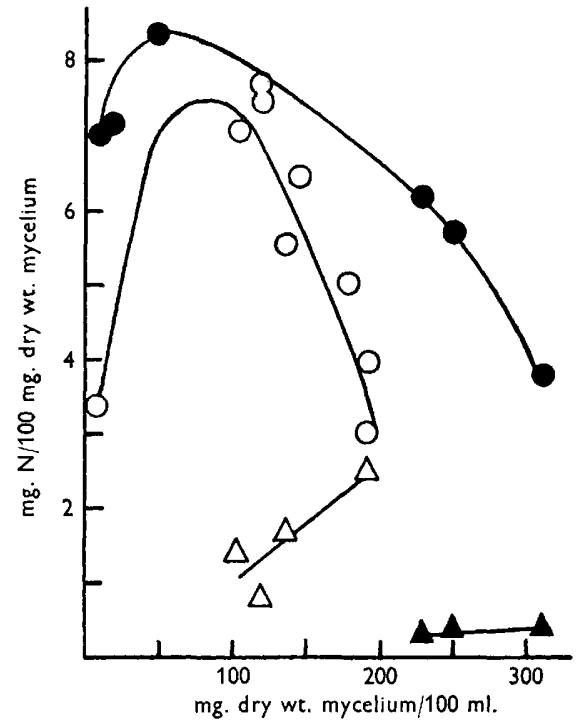

Fig. 2

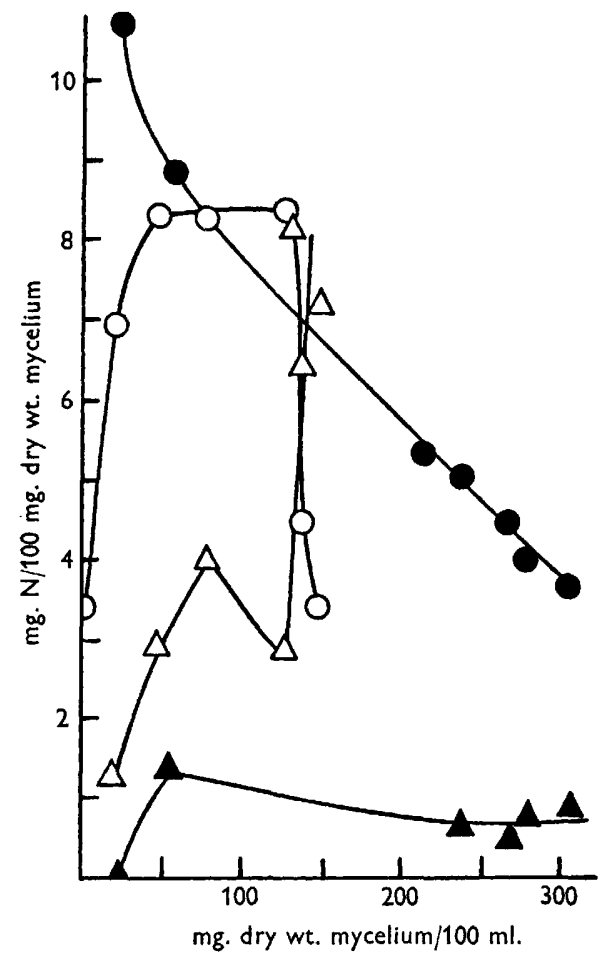

Fig. 3

Figs. 2, 3. Nitrogen incorporated and excreted by Aspergillus oryzae at low (Fig. 2) and high (Fig. 3) mechanical stress. Organic- $\mathrm{N}$ in mycelium ( $\mathrm{N}$ incorporated) was estimated in both large-inoculum $(-\infty)$ and small-inoculum $(\mathrm{O}-\mathrm{O})$ cultures. Organic-N in filtrate ( $\mathbf{N}$ excreted) was also estimated in both large-inoculum $(\Delta-\Delta)$ and smallinoculum $(\triangle-\triangle)$ cultures.

\section{Organic nitrogen in mycelium and in filtrate}

Conditions of low mechanical stress are considered first. When organic- $\mathbf{N}$ in the mycelium was estimated, a large-inoculum culture showed a high $\mathbf{N}$ content in the mycelium in the early stages (Fig. 2); later, there was a steady decrease in this value. In a small-inoculum culture, Fig. 2 shows that the $\mathbf{N}$ content was considerably lower in early and late stages and probably had a lower maximum. The amount of organic- $\mathbf{N}$ in the filtrate was generally low in a large-inoculum culture (Fig. 2). A small-inoculum culture showed a more pronounced increase in organic- $\mathbf{N}$ in the filtrate. From these results at low mechanical stress a pattern of $\mathbf{N}$ metabolism may be deduced. The mycelium from a large-inoculum culture is the more efficient, as it 
assimilates more $\mathrm{N}$. Further, as organic- $\mathrm{N}$ in the filtrate represents $\mathrm{N}$ excreted by the mould (for inorganic- $\mathrm{N}$ only is present in the initial medium), the results show that a large-inoculum culture excreted very little N. Conversely, in small-inoculum cultures, the lower $\mathrm{N}$ content of the mycelium and the higher excretion of organic- $\mathrm{N}$ are indicative of inefficiency in $\mathrm{N}$ utilization and assimilation.

Corresponding experiments were performed at high mechanical stress (Fig. 3). Organic- $\mathbf{N}$ in the mycelium at various stages of growth was examined. Figure 3

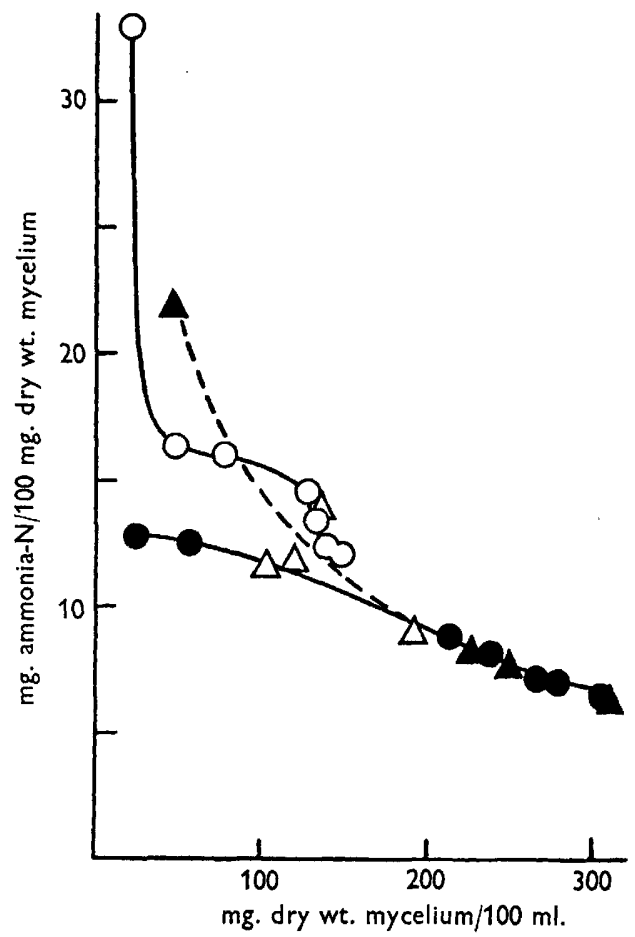

Fig. 4. Ammonia nitrogen metabolized by Aspergillus oryzae at low and high mechanical stress. The values for large-inoculum $(\Delta-\Delta)$ and small-inoculum $(\triangle-\triangle)$ cultures at low mechanical stress are shown by the broken line. The values for large-inoculum ( and small-inoculum $(\mathrm{O}-\mathrm{O})$ cultures at high mechanical stress are shown by the continuous lines.

shows that in a large-inoculum culture the results corresponded very closely to those obtained at low mechanical stress. The small-inoculum mycelium showed a decrease in $\mathrm{N}$ content, beginning at about the same point ( $130 \mathrm{mg}$. dry wt. mycelium/100 ml.) as at low mechanical stress but this decrease was much more pronounced at high stress. As was found at low mechanical stress, the amount of organic- $\mathrm{N}$ in the filtrate was smaller in a large-inoculum culture. A small-inoculum culture showed an increase of organic- $\mathrm{N}$ in the filtrate as at low mechanical stress, but the increase was more pronounced (Fig. 3). Thus under conditions of high mechanical stress also, the pattern of assimilation and excretion of $\mathbf{N}$ indicates that the large-inoculum culture was the more efficient. It appears, moreover, that at a given point, mycelium of a small-inoculum culture underwent a marked change in metabolic behaviour, 
as was shown by a large and rapid excretion of $\mathrm{N}$. This occurred while the mycelium content of the culture was still increasing, just before maximal growth; it did not take place during what is usually called the phase of decline or the autolytic phase. A comparison of Figs. 2 and 3 shows that an increase in mechanical stress accentuated these differences in the behaviour of large-inoculum and small-inoculum cultures.

\section{Metabolism of ammonia- $N$}

At low mechanical stress there was little distinction between a large-inoculum culture and a small-inoculum one in the specific amount of ammonia-N metabolized (see Fig. 4). When, however, the mechanical stress was increased, the smallinoculum culture utilized specifically more ammonia- $\mathbf{N}$ than did a large-inoculum culture. Generalizations about the efficiency of a culture cannot safely be made from this particular aspect of $\mathbf{N}$ metabolism; efficiency in $\mathbf{N}$ metabolism should perhaps be measured not so much by how little $\mathbf{N}$ is utilized to produce a given weight of mycelium, as by what is done with the $\mathrm{N}$ so utilized. Figure 4 shows that by altering the mechanical stress, the effect of size of inoculum on the amount of ammonia-N utilized was also altered. At low mechanical stress there was no evident influence of inoculum size; at high mechanical stress, the small-inoculum culture metabolized more ammonia- $\mathbf{N}$ than did the large-inoculum culture.

\section{DISCUSSION}

It should be remembered that in Figs. 2, 3 and 4, points in vertical line represent the same weight of mycelium. The effects, then, are not due to differences in amount of mycelium, but are specific differences. Two cultures of the same mycelium content are not of the same age, because a small-inoculum culture takes longer to reach a given mycelium content than does a large-inoculum culture. That is to say, where points are in vertical line, up to maximal growth, the small-inoculum culture is composed of older mycelium.

The results show that there may bevery great changes (increases as well as decreases) in $\mathbf{N}$ content of mycelium during culture development. This invalidates the use of $\mathbf{N}$ content as sole measure of growth. When there is an increase in dry wt. mycelium, it implies that synthesizing reactions are involved with resultant formation of new cellular substance which can suitably be called 'growth'. It is also doubtful whether the $\mathrm{N}$ content of mycelium is a measure of 'living protoplasm' because some of the cellular $\mathbf{N}$ might act as storage $\mathbf{N}$; furthermore a comparison of the respiration activity of this mould (Meyrath \& McIntosh, 1963) with its cellular $\mathrm{N}$ reveals no proportionality. These investigations show that the total synthesizing activity (as expressed by dry wt.) and the specific assimilation of $\mathrm{N}$ can be affected by inoculum size.

The decrease in $\mathbf{N}$ content during the major part of the development of cultures from large and small inocula was very pronounced and is likely to be due to inefficiency of assimilation. Here again it appears that the cultures underwent an ageing process similar to that described for carbon metabolism (Meyrath \& McIntosh 1963); a small-inoculum culture assumed the properties of an old large-inoculum culture when it reached the initial stages of growth of the latter. A decrease in $\mathbf{N}$ content of the mycelium during cultivation, although generally less pronounced, 
was also observed with other fungi (Cochrane, 1958; Keller, 1952; Schelling, 1952). Taking into consideration the results obtained from several moulds submitted to tests on size of inoculum (Meyrath \& McIntosh, 1963), it appears that the described types of effects of size of inoculum among fungi will occur more frequently than might have been anticipated.

We wish to acknowledge the skilled technical assistance given by $\mathrm{Mr}$ J. McElroy and to thank Professor E. O. Morris for his interest and encouragement.

\section{REFERENCES}

Cochrane, V. W. (1958). Physiology of Fungi, New York: John Wiley and Sons Inc.

Keller, H. G. (1952). Untersuchungen über das Wachstum von Cenococcum graniforme (Sow.) Ferd. et Winge auf verschiedenen Kohlenstoffquellen. Ein Beitrag zur Kenntnis der Physiologie der mykorrhizabildenden Pilze. Thesis, Fidgenössische Technische Hochschule, Zürich.

MeYrath, J. (1962). Size of inoculum and growth kinetics of moulds. Experientia, 18, 41.

Meyrath, J. (1963). Influence of the size of inoculum on various growth phases in Aspergillus oryzae. Antonie van Leeuwenhoek J. Microbiol. Serol. 29, 57.

Meyrath, J. \& McIntosh, A. F. (1963). Size of inoculum and carbon metabolism in some Aspergillus species. J. gen. Microbiol. 33, 49.

Schelling, C. L. (1952). Zur Kenntnis der Physiologie von Mycelium Radicis atrovirens Melin mit besonderer Berücksichtigung der Verwertbarkeit verschiedener Kohlenstoffquellen. Thesis, Eidgenössische Technische Hochschule, Zürich. 